\title{
Writing creatively to catch flickers of 'truth' and beauty
}

\begin{abstract}
This paper examines creative writing in academia through writing as a form of inquiry. Writing about lived experiences is a creative and empathetic form of ontology that unravels the flickers of 'truth' and beauty that elude the rational mind. Writing creatively requires letting go of the rigid structures of dominant academic discourse to write the unknown into being. To experience writing's potential, academics need to pay attention the resonance felt through their bodies and memories to uncover these flickers to writing and living well.
\end{abstract}

\section{Catching the flickers}

There is subtle truth, magical truth, lyrical truth, visceral truth, truth that implies verisimilitude (Rinehart 1998, 200).

Creative writing's open-ended, metaphorical and expressive form enables writers to draw out and capture what has yet to materialise. It allows writers to convey the fluid, mysterious and constantly evolving nature of lived experience, and can evoke a resonance that animates. This paper illustrates how academic writers can write creatively to capture flickers of hidden meaning and generate powerful stories to live by. To uncover the steps in this process, I have read examples of creatively written academic texts like a curious child who pulls apart her favourite toy to understand how it works. As I deconstruct examples of such writing, I notice how ideas can emerge from fleeting flickers of intuitive understanding that are intuited through a half light, and can easily be overlooked, as "they never come at you all at once, more like in fits and starts over extended periods of time, small isolated events that seem to be unrelated to each other or to anything else," and yet during other moments, their frequency makes them difficult to ignore, as "these so-called isolated happenings cluster together and their import can no longer be ignored, denied or repressed" (Frentz 2011, 798). Catching these flickers requires a certain level of skill and craftsmanship, which can be acquired and refined through practice.

The first steps of writing are the most difficult as there is only a faint trace of a trail to follow. It begins when I feel a weight bearing down on my consciousness, which I tentatively trace out with my words. The pathway is unknown, but the general destination is clear. I write to uncover writing's life-evoking potential to guide us towards a better life, as Bochner (2012) relates, "Those of us who have been seduced by the call of stories realise there may be no better way to come to terms with how we want to live and what we can understand and say about how others live than to listen to and converse with their stories" (162). Bochner proposes that academics should write to understand life rather than to simply dispense knowledge. This act of putting the isolated flickers together occurs in the dim spaces of the subconscious, but the more it is practiced, the more fluently we can decipher and construct a richer narrative for our lives. Unpacking this process of writing creatively to pursue the flickers can accordingly help us to navigate the mind's hidden mechanisms to write and to live well. 


\section{Reflexivity and paying attention}

Writing as inquiry is about paying attention and bringing into being to what is possible and what has yet to come. Lugli $(1986,123)$ describes this process of awareness as, "an intermediate, highly particular state akin to a sort of suspension of the mind between ignorance and enlightenment that marks the end of unknowing and the beginning of knowing." There is a space between knowing and the unknown that presents a fertile ground for discovery. Pearce (2010) also suggests that knowing is preceded by a liminal space that, ". . . border[s] between the not-yet and the yet-to-come and between dichotomies of virtual and actual, being and becoming, between "life" and "power," and of recognition and representation" (903). She expresses how knowing lurks within suggestive meaning, which hints towards hidden meaning and potential. Pearce (2010) conveys how the suspension of judgment is required to pursue alternative possibilities, as she states, "We guess at meanings, structure our sense making, and consider both possibilities and impossibilities" (902). hooks (2000) relates a similar point as she explains:

We write to find secrets in experience that are obscured from ordinary sight: to uncover hidden coherences in what seems to be a mere jumble of unrelated events and details, and incoherencies in what appears to be strictly ordered; to make transparent what is opaque, and to expose in what seems transparent (5).

As we become more receptive to new possibilities for inquiry, we may begin to notice potential ideas everywhere. This state of openness allows us to, “. . . linger longer at those sites where we might otherwise collapse into our habitual processes and understandings" (Pearce 2010, 903). We can see subtle movements as we linger and look beyond what first meets the eye. MacLure (2013) speaks of seeing hidden flickers of meaning as a form of wonder. She relates how these flickers may appear as a, “. . a comment in an interview, a fragment of a field note, an anecdote, an object, or a strange facial expressionseems to reach out from the inert corpus (corpse) of the data" (228) and explains how these glimmers of something fascinate us with their potential to "animate further thought," even though they may not be compatible with our existing thoughts (228). Once these glimpses have been captured by our consciousness, we can start unravelling them.

Writing to catch the flickers involves reflexivity, and the capacity to suspend judgment to catch something that is overlooked or misconceived. Reflexivity cultivates a nuanced sight as it allows the viewer to reconsider their frames of reference and to consider alternative possibilities that account for subtle differences or shades in meaning. Murray (1992) asserts that beginner writers may be unable to catch glimpses as they 'do not value' their reactions enough and dismiss them for being every day, ordinary and unimportant. He writes about having learnt over time to find delight in nondescript encounters through paying attention to his life. Murray (1992) reveals how this reflexive mindset prevents him from ever becoming bored or losing interest in the world, and he suggests that writers need to have the "essential innocence or arrogance" to believe in the value of their everyday encounters to write their experiences into being, as if the "experience - observation, thought or feeling - ha[d] not existed until I write it" (15). In her description of threshold concepts of creativity, Adsit (2018) regards reflexivity as a way of separating the knower from the known by destabilising notions of "single ways of knowing" (136). Through being reflexive about our life encounters, we can discern and adopt various possibilities of seeing to gain new understandings. 
Reflexivity allows us to appreciate the emancipatory potential of inquiry. McMahon (1996) illustrates this point as she ponders her interest in researching motherhood. She follows a trail of clues that ultimately lead her to the dilemma of being a woman who lives a child-less existence. McMahon's (1996) research allow her to confront the traditional norms of womanhood that she has experienced from birth, which leaves her disconcerted by the feeling that something is not as it should be. She examines what motivates a woman to become a 'mother' through reflexively tracing traditional notions of womanhood confronted from childhood. This investigation helps her to unlock her dilemma of being a woman who is not a 'mother' and teaches her that research is a boundless place where there is no border between living and inquiry, and no governing factor that determines what research should be about and not. Reflexivity can accordingly lead researchers back to themselves by revealing their subjectivities and the broader social forces that have shaped them.

\section{Unlearning and letting go of what distracts}

To catch a glimpse of what has yet to come, academic writers need to let go of what distracts. Pursuing the flickers of meaning may be difficult for academics, who exist in a field where value and impact is assessed by what is measurable and quantifiable. Dominant academic writing discourse can inhibit reflexivity as it prizes the empirical voice over the personal one. Convinced that objectivity is the 'only' legitimate approach, academics may adopt the omniscient voice of science over their unique frames of reference, as hooks (2000) acknowledges, "irrespective of our locations, we are all vulnerable. We can all be had, co-opted, bought. There is no special grace that rescues any of us" (7). We are all susceptible to being distracted or 'bought out' as we replicate and privilege these norms that makes our writing impenetrable and inaccessible to others (Bochner 2012). Richardson (2002) explains how the everyday act of living or writing is imbued with these constructions of power, as she states, "Wherever truth is claimed, so is power; the claim to truth is also a claim to power" (415). The topics and forms of inquiry that lie outside this model are dismissed, and the rigid academic writing conventions subsequently distracts, as Harper (2019) explains, “. . . we produce actions and reactions on the surface of understanding ... pointing to their outcomes. . get[ing] further from the truth" (394). As we write and publish such work, we may still experience a nagging sense that something is amiss. KG reflects this dissatisfaction with academic writing in his retirement, stating, "Academic writing is something that in the end of the day one doesn't feel good about. All you've done is chop down trees and trade words with people" (Ellis et al. 2017, 578). He expresses the emptiness felt over a career of writing 'academically' and urges us to find more vibrant and intrinsically forms of expression.

Academic writing draws us further away from ourselves when it prioritises external facts over lived experience. This artificial separation between lived experience and theoretical knowledge can lead to dry and lifeless writing that distracts us from writing's potential power to access the mysteriousness of knowing. An over-reliance of facts and figures consequently becomes the stuff that distracts. In 'The Ties That Bind Us, the Shadows That Separate Us,' Poulos (2006) relates this growing inability between the difference between a truth and lie may eventually suffocate us. Poulos (2006) describes how a shadow descends upon his family after the death of loved ones, which causes his family to harbor little secrets that grow into a life of secrecy. His family struggles to see anything clearly through this fog, as he relates, 'Engulfed in shadow, how do you discern the difference between truth and lie, between story and secret? (Poulos 2006, 103) He explains how this protective silence becomes an impenetrable wall that soon 
suffocates them. Soon all sense of truth is lost. In a similar way, the shadows perpetuated by conventional writing discourse can hide the flickers of personal 'truths.' We can become less sensitised towards such knowledge over time, as we discount and dismiss what can't be measured.

By occupying worlds that consist of subtle shades of colour rather than black and white, we can see how language can control perception by shaping meaning in multiple ways. Writing to inquire helps us to unmask the habitual and taken for granted assumptions and practices that constrain. Such receptivity is vital to prevent the loss of tacit understandings that sit beneath the surface. Poulos (2008) reflects on these 'signs' that inhabit our worlds. He depicts one involving a painting of a red heart on a black background, which he notices lying abandoned on the floor. He is disturbed by the large axe that pierces its centre and asks himself, 'What does it mean? What does it say about the person who painted it?' He later reflects:

\begin{abstract}
And this "sign" got me to thinking about the connections between consciousness and communication, between dream and reality, between art and madness, between thinking and connecting with others, between loneliness and community, between secrets and stories - all while I was pondering this idea that sometimes we are "gripped" by a dream, or by an image, or by a story, or by a secret, or by a burst of insight or creativity or even genius (Poulos 2008, 49).
\end{abstract}

We can begin the process of unravelling its hidden layers by reflexively lingering within a resonating moment. Meredith (2011) provides an example by explaining how a lecturer of literature teaches him a well-known passage within a short story, first by reinforcing what was, "already understood," and then by presenting it in an entirely different way through drawing attention to the "pattern of images, symbols and structures that had been invisible" (75). Meredith (2011) describes his new understanding as, "... [being] akin to the feeling in childhood when the shapes on the page in front of you suddenly start to yield up meanings. . beyond comprehension and appreciation to a profound apprehension of the piece in which not only is disbelief suspended but also the sense of time and even of the self" (75). He demonstrates how this careful process of unravelling the flickers and help us to unpack "relevant human experiences" within seemingly random and ordinary encounters (Todres \& Galvin 2008, 581).

Writing as inquiry can increase the scope, depth, relevance and reflexivity of our work. Richardson (2002) explains this notion through an analogy of how a crystal can refract light in multiple directions, as she conveys, "Crystals are prisms that reflect externalities and refract within themselves, creating different colors, patterns, and arrays, casting off in different directions" (13). She asserts that our writing becomes interesting through its ability to, "pose [a] mystery that can be read on multiple levelsinteractional, social structural, and spiritual level" that moves us onto bigger and more challenging questions (Richardson \& Lockridge 1998, 335). Engaging in research through a refractive lens means disclosing unopened or multiple avenues of thought to reveal the complexity of the knowing process, as Richardson (1994) writes:

[Crystallization] combines symmetry and substance with an infinite variety of shapes, substances, transmutations, multidimensionalities, and angles of approach... Crystallization provides us with a deepened, complex, thoroughly partial understanding of the topic. Paradoxically, we know more and doubt what we know (522). 
Richardson (1994) provides another illustration of writing as a process of opening drawers within a metaphorical desk that consist of multiple drawers made from different raw materials, which hold her post structural sensibilities and gives birth to her autoethnographic self. She explains how these drawers reflect the different aspects of writing that lead her to a richer understanding of herself.

\section{Crafting Resonance}

Writing is animated through resonance, which provides an answer to the question, "Where can we find inspiration to actually write the lived experience and not just write about it?" (Meier and Wegener 2017, 193). Resonance allows us to access tacit knowledge that is sensed and "embodied, sometimes tacit, and tied to experiences or memories"(Meier \& Wegener 2017, 193). It can be the impetus of inquiry, as we sense a hidden truth that has yet to emerge. Resonance can be found in different artefacts of our lived experiences, such as our memories. Poulos (2016) reveals how he learns to embrace his memories as he senses the meaning hiding within them. His memories reveals the first glimmers of a story, which he pursues until a path forms. He persists despite the challenges of following an unknown path, as he realises their potential to draw forth meaning. Poulos (2016) searches memories that make a particularly strong impression through eliciting, arousing and awakening emotions that hold the key to insight and understanding.

Resonance can be felt through the body. Maclure (2012) writes that understanding originates from the senses, as she states, "We may feel the wonder of data in the gut, or the quickening heartbeat, as well as in the cerebral disappointment of failing to find the right code or category in which to park a particular piece of data" (229). Todres and Galvin (2008) touch upon this embodied nature of inquiry. They explain how understanding aesthetic meaning often relies on the body, as the, ". . . the lived body as holistically participates in its living, feeling and moving that provides the experiential ground of what words are about. . It is experiential before it is logical or made into a pattern through reflection and language" (574). We engage the world through our bodies, which makes it the source of all knowledge. They assert that we need to pay attention to our physical senses as, "the lived is greater than the known" (575). What we register on a conscious level is only a sliver of what our bodies are exposed to. Todres and Galvin (2008) depict this form of ontology as a, "body-based, empathic imagination- it is about paying attention to what the presence of the communicated phenomenon is like when we stand before it in an embodied way" (576-577). They believe that embodied listening helps us to, "carry forward the meanings that these words open up" (569). Our bodies capture the flickers that can bring meaning to life, and we respond to this knowledge through our bodies. Knowing accordingly exists as a circular movement by beginning and ending with the body.

Writing becomes resonant when a writer deeply connects to their words. Words come alive as they retain a writer's emotions and evoke the very sensations of their encounters. To write with resonance, you need to first search out what resonates deeply with you. Through drawing upon material that interests and draws you in, it is more likely that you will be able to craft writing that resonates with others (Wikan 2012). Bochner (2002) argues that a writer's trustworthiness and their "emotional credibility, vulnerability and honesty," is what deeply impacts the reader's heart and mind (271). He asserts the value of writing poetically to," . . to grasp or seize the possibilities of meaning, which is what gives life its imaginative and poetic qualities ... that is adequate to [conveying] the obscurity and darkness of 
experience" (270). Bochner (2018) accordingly depicts writing as a, "poetic science of human being" that allows those who are studied "to live on the page" (365). Artistic forms of representation and literary forms of text allow us to capture the myriad of possible meanings that enable a, "coming-to-see" or "coming-to-hear" of meaning (Adsit 2018, 134). For example, an abundance of detail can add flesh to our writing, whilst a complex narrative structure allows us to visualise, "the flesh and blood emotions of people coping with life's contingencies" (Bochner 2000, 271), allowing language to become a mirror that "disclose[s] hidden details of private life" (Bochner 2012, 158). Such writing mimics the rich complexities of life. This ability to craft our writing to depict the fullness of encounters, as the "artistic gives space to the sensuous, to the embodied, to the evocative" (Pelias 2015, 610). Moreover, writing with resonance can deepen the inner poet and the humanity of the writer, in which, ". . . the interrogation of our own emotional responses to the work we do that might, in the end, sharpens and strengthen the moral sensitivity we bring to the page" (Van Maanen 2010, 341).

Writing with resonance reflects the open and expansive mindset of the writer. Its form is equally open ended and expansive, allowing readers to "draw whatever experiences [they] carry with ... into the reading and usage of it" (Meier \& Wegener 2017, 200). Such writing may appear to be unfinished as it ends without any authoritative declaration of 'truth;' instead, it generates multiple avenues for interpretation and response (Meier \& Wegener 2017; Helin 2015). It has a strong impact on readers, as its open-endedness elicits a deeper level of engagement. Resonance subsequently enables readers to engage authentically with a writer's words. Writing that resonates can stir up a reader's emotions and allow them to access or engage deeply in the writing. This common pool of experience forms a bridge that helps both readers and writers to traverse into each other's worlds (Wikan 2012, 57). As a writer's words resonate with the "readers' prior experiences, and their embodied knowledge," the reader can extend their meaning by integrating it into their own meaning making processes (Meier \& Wegener 2017, 193). Conle (1996) identifies potential impact as she explains how readers extend or alter stories by transforming them into their own. Resonance is amplified through a writer's skill in making an experience come alive. In other words, carefully crafted knowledge can facilitate a more nuanced and richly honed understanding (Wikan, 2012). Sensory details or writing that is closer to the spoken language can activate resonance and reduce the distance between the reader and the writer. The reader's imagination becomes a fertile ground in which a text can expand, as the reader acts as a "sounding board" or a mirror that reflects the writer's intimate thoughts (Meier \& Wegener 2017, 194). Writing with resonance therefore has a strong impact as readers extend the meaning of texts through interpreting them in the light of their own experiences (Meier \& Wegener 2017).

Writing creatively to capture flickers of tacit knowing is a craft. Such craftsmanship can naturally emerge as writers access their "carnal knowledge" to achieve subtlety in "matters of timing, manner and tone" to attain greater fluidity in their writing (Eisner 2002, 382). Furthermore, writing with resonance is a craft that can be "practiced, elaborated on, and fine-tuned through encounters with other writers' texts" (Meier \& Wegener 2017, 195). Through encountering models of creative writing that resonates, academic writers can find examples to follow. They are more inclined to experiment with creative writing styles as they have personally experienced the transformative impact of writing that resonates. Pelias (2015) argues that academic writers should all continue to grow as creative writers by learning writing as a craft, as he writes: 
... the better we are as artists, the more our art will offer as a research practice. The artist with the greatest range of artistic abilities can be more articulate and more complex than the artist with limited range. Craft is a necessary methodological tool. Without craft, our efforts may be appreciated by the limited few who have a stake in the story we tell, but we will be unable to create nuanced accounts that engage broader audiences (610).

\section{Authority, authorship and witnessing}

There are flickers of hidden meaning all around us. Some of them provide us with an insight into the deeper dynamics surrounding us; during other times, these flickers can reveal our true calling, drawing us closer to who we are and who we are capable of becoming. Gorman (2018) illustrates this as she reflects on an encounter experienced early in her career:

Even in the moment, I recognized my own knee jerk acquiescence to a contrived set of standards outside the contours of individual circumstances. But I did not act in accordance with a higher truth which privileges relationship. Nor did I honor my intuition. A remnant of betrayal lingers still, the unsettling suggestion that I violated the best of what nursing should be - a natural and reciprocal relationship of care (p.3).

Gorman (2018) ponders the life lessons experienced in her early years as a hospice nurse, when she had cared for a beautifully regal former ballerina. This dignified former ballerina offers her golden anklets, which are her final prized possessions. Gorman (2018) chooses to leave this gift on the nightstand as she cannot see past the rules and regulations of her profession. Decades later, she reflexively revisits this encounter with greater embodied wisdom and empathetic understanding to sum up the essence of nursing, as she relates, "Relationships, I tell them, is the essence of practice. Intellectually I have always believed this. On a more visceral level, full metabolism has been slower in coming. I am still digesting what these experiences teach" (3). She has a 'calling' to carry the flickers around until she can understand them with the, "deepened authenticity' of passing time" (3). Through this enriched lens, she can revisit the past to declare the kind of teacher and nurse she desires to be. Gorman's story leads me to reflect on the kind of academic writer I wish to be, as rather than writing towards a point allocation system or going with the flow, I desire to write for greater coherence and agency. Gorman (2018) presents us with these two possible alternatives, revealing how a superficial understanding of our calling as academic writers can lead to superficial practices, whilst a richer view can help us to honour our mystery and to direct the story of our life.

Writing about these flickers enables them to be acknowledged and witnessed by others. Charon (2014) refers to the term 'witnessing' and as a recognition between the knower and the known, as she relates:

I have seen the by now almost inevitable dimension of reciprocity - as I gaze at a patient in an effort to recognize his or her situation, I am "gazed back at," being recognized as someone who can recognize. This process launches me on an ever-building spiral of self-making or, rather, self-seeing while repeatedly excavating the capacity within myself for future acts of the recognition of others (23).

The 'witness' is also gifted with opportunities to develop reflexivity. Through undertaking the witnessing role, a reader or listener can develop a greater sense of attunement, openness and creative empathy, and 
"grow into a more complete human being by virtue of the contact" as their sense of self becomes "interpretive, embedded, engaged, and related" as they share in each other's evocative accounts of lived experience (Charon 2009, 164). Listening with openness can cultivate reflexivity and imagination, as it involves "enlist[ing] the listener's interior resources - memories, associations, curiosities, creativity, interpretive powers, allusions to other stories told by this teller and others - to identify meaning" (Charon 2014, 46). As we begin listening to accounts of lived experiences, we are consequently collectively better able to cultivate the 'interior resources' needed to catch the flickers. Our potential for reflexivity grows as we witness the reflexivity of other writers, who reveal new ways of framing the knowledge building process (Poulos, 2013). Their examples allow us to hope for what is possible, as Pearce (2010) states, "Hope ... lives in the spaces between our lived realities and how things could be otherwise" (902).

\section{Final flickers}

Similar to how our lives can grow organically and flow unscripted, I have diverted off course whilst writing this paper. I started this paper with the hope of finding a blueprint for writing and living well but have come to realise that this blueprint often emerges in retrospect. The end goal has been a mirage as I have tried to forego the steps needed to reach it. A life well lived does not equate to a life without confusion or detours, in the same way that good writing rests on the missteps that create reflexive pauses. In fact, the blotches can become the focal points that draw our eye, and as we stumble our way through lesser known paths, we can create ourselves into being as to following a predetermined script. This process of stumbling into knowing by deviating from the well-trodden track, reveals how creative writing involves "disconnecting from established or 'correct' processes" to seek alternatives (Adsit, 2018, 136).

Our journey through the academic writing process often follows an unknown path. Along this journey we may glimpse flickers of hidden meaning that present an opportunity for learning. These flickers appear through rifts and ruptures and can generate emotions strong enough to explore murky waters to uncover hidden 'truth.' We can use our skills as writers and readers to become attuned to these flickers to increase our receptivity to life. Murray (1991) asserts that all writing is autobiographical, and we are able to know about ourselves through what we choose to write about. Richardson (1997) explores this notion of writing the 'self into being' as she poses the question, "How does what we write affect who we become?" (295) She proposes that writing is shaped by our "... state of mind- how you see, how you sense life, think about life, imagine life to be, and only then how you go about bringing life onto the page, making those choices that allow you to create life with words" (Richardson \& Lockridge 1998, 333). Each moment holds this potential to generate the light of self revelation and deep understanding, as Gonzales (2012) writes, "You're still here. That means that you can do something" (209). We are still here. So, what does this mean? This means that we can take steps that illuminate, or take none at all. Creative writing in its "visceral, unabbreviated form" is about luminescence (Harper 2019, 394). The call of academic writing is to luminate and to unravel words that cuts through the distractions and emanates light and life, and as we write ourselves into a bright future, we seek understanding and a "hope for a compassion that has not yet arrived," trusting that we will be able to glimpse and unravel the flickers of meaning when they arrive (Murray 1991, 67). 



\section{References}

Adsit, J. 2018. "Creative Writing and the limits of Naming What We Know: threshold concepts from aesthetic theory and creativity studies in the literary writing curriculum." New Writing: The International Journal for the Practice and Theory of Creative Writing 15:2 131-139.

Bochner, A. 2018. "Unfurling Rigour: On Continuity and Change in Qualitative Inquiry." Qualitative Inquiry 24:6 359-368.

Bochner, A. 2012. "On first-person narrative scholarship: Autoethnography as acts of meaning." Qualitative Inquiry 22:1 155-164.

Bochner, A. 2002. Criteria Against Ourselves. Qualitative Inquiry 6:2 266-272.

Charon, R. 2014. "Narrative Reciprocity. Narrative Ethics: The Role of Stories in Bioethics." Hastings Center Report 44:1 21-24

Charon, R. 2009. "Commentary on "Creative Expressive Encounters in Health Ethics Education: Teaching Ethics as Relational Engagement.” Teaching and Learning in Medicine 21:2 163-165.

Conle, C. 1996. "Resonance in preservice teacher inquiry." American Educational Research Journal 33 297-325.

Eisner, E. 2002. "From Episteme to Phronesis to Artistry in the Study and Improvement of Teaching." Teaching and Teacher Education 18:4 375-385.

Ellis et al. 2017. "Living the Post-University Life: Academics Talk About Retirement." Qualitative Inquiry 23:8 575-588.

Frentz, T. 2011. “Is It Time Yet?” Qualitative Inquiry 17:9 798-804.

Gonzales, L. 2012. Surviving Survival: The Art and Science of Resilience. W.W. Norton \& Company, Inc.: New York.

Gorman, G. 2018. "This Girl is on Fire: Seeking a Home for the Narrative." Qualitative Inquiry Advanced Online Publication. https://doi.org/10.1177/1077800418786694

Harper, G. 2019. "Trace and Luminescence." New Writing: The International Journal for the Practice and Theory of Creative Writing 16:4 393-394

Helin, J. 2015. "Writing process after reading Bakhtin: From theorized plots to unfinalizable "Living" events." Journal of Management Inquiry 24 174-185

hooks, b. 2000. Remembered Rapture: Dancing with Words. JAC 20:1 1-8. 
Lugli, A. 1986. “Inquiry as collection.” Res 109-124.

MacLure, M. 2012. “The Wonder of Data.” Cultural Studies <-> Critical Methodologies 13:4 228-232.

McMahon, M. 1996. “Significant Absences.” Qualitative Inquiry 2:3 320-336

Meier, N., \& Wegener, C. 2017. “Writing with Resonance.” Journal of Management Inquiry 26:2 193201.

Meredith, C. 2011. "Miller's answer: Making, Saying, and the Impulse to Write." New Writing: The International Journal for the Practice and Theory of Creative Writing 8:1 71-89.

Murray, D. 1992. “A Writer's Habits.” The Writer 105:1 14-17.

Murray, D. 1991. "All Writing is Autobiography." College Composition and Communication $42: 166-$ 42.

Pearce, C. 2010. “The Life of Suggestions.” Qualitative Inquiry 16:10 902-908.

Pelias, R. J. 2015. "A Story Located in "Shoulds": Toward a Productive Future for Qualitative Inquiry." Qualitative Inquiry 21:7 609-611.

Poulos, C. N. 2016. "An Autoethnography of Memory and Connection. Qualitative Inquiry." Qualitative Inquiry 22:7 $552-558$

Poulos, C. N. 2013. "Writing my way through memory, autoethnography, identity, hope." In Handbook of autoethnography, edited by Stacey. Holman Jones, Tony.E. Adams, and Carolyn. Ellis , 465-477. Walnut Creek, CA: Left Coast Press.

Poulos, C.N. 2008. "Narrative Conscience and the Autoethnographic Adventure: Probing Memories, Secrets, Shadows, and Possibilities." Qualitative Inquiry 14:1 46-66.

Poulos, C. N. 2006. "The Ties That Bind Us, the Shadows That Separate Us." Qualitative Inquiry 12:10 96-117.

Richardson, L. 2002. "Writing Sociology.” Cultural Studies <-> Critical Methodologies 2:3 414-422

Richardson, L., \& Lockridge, E. 1998. "Fiction and Ethnography: A Conversation." Qualitative Inquiry 4:3 328-336.

Richardson, L. 1997. "Skirting a Pleated Text: De-Disciplining an Academic Life." Qualitative Inquiry 3(3): 295-303. 
Richardson, L. 1994. "Writing: A method of inquiry." In Handbook of qualitative research, edited by Norman.K. Denzin \& Yvonna.S. Lincoln, 516-529. Thousand Oaks, CA: Sage Publications.

Rinehart, R. 1998. "Fictional Methods in Ethnography: Believability, Specks of Glass, and Chekov." Qualitative Inquiry 4:2 200-224.

Todres, L. \& Galvin, K. T. 2008. "Embodied interpretation a novel way of evocatively re-presenting meanings in phenomenological research.” Qualitative Research 8:5 568-583.

Wikan, U. 2012. Resonance. Beyond the words. Chicago, IL: University of Chicago Press.

Van Maanen, J. 2010. "You gotta have grievance: Locating heartbreak in ethnography.” Journal of Management Inquiry $19338-341$. 